\title{
Instrucción sobre algunos aspectos de la "teología de la liberación"
}

Sagrada Congregación para la Doctrina de la Fe

\section{INTRODUCCION}

El Evangelio de Jesucristo es un mensaje de libertad y una fuerza de liberación. En los últimos años esta verdad esencial ha sido objeto de reflexión por parte de los teólogos, con una nueva atención rica de promesas.

La liberación es ante todó y principalmente liberación de la esclavitud radical del pecado. Su fin y su término es la libertad de los hijos de Dios, don de la gracia. Logicamente reclama la liberación de múltiples esclavitudes de orden cultural, económico, social y político, que, en definitiva, derivan del pecado, y constituyen tantos obstáculos que impiden a los hombres vivir según su dignidad. Discernir claramente lo que es fundamental y lo que pertenece a las consecuencias es una condición indispensable para una reflexión teológica sobre la liberación.

En efecto, ante la urgencia de los problemas, algunos se sienten tentados a poner el acento de modo unilateral sobre la liberación de las esclavitudes de orden terrenal y temporal, de tal manera que parecen hacer pasar a un segundo plano la liberación del pecado, y por ello no se le atribuye prácticamente la importancia primaria que le es propia. La presentacion que proponen de los problemas resulta así confusa y ambigua. Además, con la intención de adquirir un conocimiento más exacto de las causas de las esclavitudes que quieren suprimir, se sirven, sin suficiente precaución critica, de instrumentos de pensamicnto que es difícil, e incluso imposible, purificar de una inspiración ideológica incompatible con la fe cristiana y con las exigencias éticas que de ella derivan.

La Congregación para la Doctrina de la Fe no se propone tratar aqui el vasto tema de la libertad cristiana y de la liberación. Lo hará en un documento posterior que pondrá en evidencia, de modo positivo, todas sus riquezas tanto doctrinales como prácticas. 
La presente Instrucción tiene un fin más preciso y limitado: atraer la atención de los pastores, de los teblogos y de todos los fieles, sobre las desviaciones y los riesgos de desviación, ruinosos para la fe y para la vida cristiana, que implican ciertas formas de teología de la liberación que recurren, de modo insuficientemente crítico, a conceptos tomados de diversas corrientes del pensamiento marxista.

Esta llamada de atención de ninguna manera debe interpretarse como una desautorización de todos aquellos que quieren responder generosamente y con auténtico espiritu evangélico a "la opción preferencial por los pobres." De ninguna manera podrá servir de pretexto para quienes se atrincheran en una actitud de neutralidad y de indiferencia ante los trágicos y urgentes problemas de la miseria y de la injusticia. Al contrario, obedece a la certeza de que las graves desviaciones ideológicas que señala conducen inevitablemente a traicionar la causa de los pobres. Hoy más que nunca, es necesario que la fe de numerosos cristianos sea iluminada y que éstos estén resueltos a vivir la vida cristiana integralmente, comprometiéndose en la lucha por la justicia, la libertad y la dignidad humana, por amor a sus hermanos desheredados, oprimidos o perseguidos. Más que nunca, la Iglesia se propone condenar los abusos, las injusticias y los ataques a la libertad, donde se registren y de donde provengan, y luchar, con sus propios medios, por la defensa y promoción de los derechos del hombre, especialmente en la persona de los pobres.

\section{Una aspiración}

1. La poderosa y casi irresistible aspiración de los pueblos a una liberación constituye uno de los principales signos de los tiempos que la Iglesia debe discernir e interpretar a la luz del Evangelio.' Este importante, fenómeno de nuestra época tiene una amplitud universal, pero se manifiesta bajo formas y grados diferentes según los pueblos. Es una aspiración que se expresa con fuerza, sobre todo en los pueblos que conocen el peso de la miseria y en el seno de los estratos sociales desheredados.

2. Esta aspiración traduce la percepción auténtica, aunque oscura, de la dignidad del hombre, creado "a imagen y semejanza de Dios" (Gén 1, 26-27), ultrajada y despreciada por las múltiples opresiones culturales, políticas, raciales, sociales y económicas, que a menudo se acumulan.

3. Al descubrirles su vocación de hijos de Dios, el Evangelio ha suscilado en el corazón de los hombres la exigencia y la voluntad positiva de una vida fraterna, justa y pacífica, en la que cada uno encontrará el respeto y las condiciones de su desarrollo espiritual y material. Esta exigencia es sin duda la fuente de la aspiración de que hablamos.

4. Consecuentemente, el hombre no quiere sufrir ya pasivamente el aplastamiento de la miseria con sus secuelas de muerte, enfermedades y decadencias. Siente hondamente esta miseria como una violación intolerable de su dignidad natural. Varios factores, entre los cuales hay que contar la levadura evangelica, han contribuido al despertar de la conciencia de los oprimidos.

5. Ya no se ignora, aun en los sectores todavía analfabetos de la pobla- 
ción, que, gracias al prodigioso desarrollo de las ciencias y de las técnicas, la humanidad, en constante crecimiento demográfico, seria capaz de asegurar a cada ser humano el minimo de los bienes requeridos por su dignidad de persona humana.

6. El escándalo de irritantes desigualdades entre ricos y pobres ya no se tolera, sea que se trate de desigualdades entre países ricos y países pobres o entre estratos sociales en el interior de un mismo territorio nacional. Por una parte, se ha alcanzado una abundancia, jamás conocida hasta ahora, que favorece el desplifarro; por otra, se vive todavia en un estado de indigencia marcado por la privación de los bienes de estricta necesidad, de suerte que no es posible contar el número de las victimas de la mala alimentacion.

7. La ausencia de equidad y de sentido de la solidaridad en los intercambios internacionales se vuelve ventajosa para los paises industrializados, de modo que la distancia entre ricos y pobres no deja de crecer. De ahi, el sentimiento de frustración en los pueblos del Tercer Mundo, y la acusación de explotación y de colonialismo dirigida contra los países industrializados.

8. El recuerdo de los daños de un cierto colonialismo y de sus secuelas crea a menudo heridas y traumatismos.

9. La Sede Apostólica, en la linea del Concilio Vaticano II, así como las Conferencias Episcopales, no han dejado de denunciar el escándalo que constituye la gigantesca carrera de armamentos que, junto a las amenazas contra la paz, acapara sumas enormes de las cuales una parte solamente bastaria para responder a las necesidades más urgentes de las poblaciones privadas de lo necesario.

\section{Expresiones de esta aspiración}

1. La aspiración a la justicia y al reconocimiento efectivo de la dignidad de cada ser humano requiere, como toda aspiración profunda, ser iluminada y guiada.

2. En efecto, se debe ejercer el discernimiento de las expresiones, teóricas y prácticas, de esta aspiración. Pues son numerosos los movimientos políticos y sociales que se presentan como portavoces auténticos de la aspiración de los pobres, y como capacitados, tambien por el recurso a los medios violentos, a realizar los cambios radicales que pondrian fin a la opresión y a la miseria del pueblo.

3. De este modo con frecuencia la aspiración a la justicia se encuentra acaparada por ideologias que ocultan o pervierten el sentido de la misma, proponiendo a la lucha de los pueblos para su liberación fines opuesıos a la verdadera finalidad de la vida humana, y predicando caminos de acción que implican el recurso sistemálico a la violencia, contrarios a una ética respetuosa de las personas.

4. La interpretación de los signos de los tiempos a la luz del Evangelio exige, pues, que se descubra el sentido de la aspiración profunda de los pueblos a la justicia, pero igualmente que se examine, con un discernimiento crítico, las expresiones, teóricas y prácticas, que son datos de esta aspiración. 


\section{La liberacion, tema cristlano}

1. Tomada en sI misma, la aspiración a la liberación no puede dejar de encontrar un eco amplio y fraternal en el corazbon y en el espiritu de los cristianos.

2. Así, en consonancia con esta aspiración, ha nacido el movimiento teológico y pastoral conocido con el nombre de "teologia de la liberación", en primer lugar en los paises de América Latina, marcados por la herencia religiosa y cultural del cristianismo, y luego en otras regiones del Tercer Mundo, como también en ciertos ambientes de los paises industrializados.

3. La expresión "teología de la liberacion" designa en primer lugar una preocupación privilegiada, generadora del compromiso por la justicia, proyectada sobre los pobres y las víctimas de la opresión. A partir de esta aproximación, se pueden distinguir varias maneras, a menudo inconciliables, de concebir la significación cristiana de la pobreza y el tipo de compromiso por la justicia que ella requiere. Como todo movimiento de ideas, las "leologlas de la liberacion" encubren posiciones teológicas diversas; sus fronteras doctrinales están mal definidas.

4. La aspiración a la liberación, como el mismo término sugiere, toca un tema fundamental del Antiguo y del Nuevo Testamento. Por tanto, tomada en sí misma, la expresion "teología de la liberación" es una expresión plenamente válida: designa entonces una reflexión teológica centrada sobre el tema biblico de la liberación y de la libertad, y sobre la urgencia de sus incidencias prácticas. El encuentro de la aspiración a la liberación y de las teologlas de la liberación no es pues fortuito. La significación de este encuentro no puede ser comprendida correctamente sino a la luz de la especificidad del mensaje de la Revelación, auténticamente interpretado por el Magisterio de la Iglesia. ${ }^{2}$

\section{Fundamentos biblicos}

1. Asi una teologia de la liberación correctamente entendida constituye una invitacion a los teólogos a profundizar ciertos temas biblicos esenciales, con la preocupación de las cuestiones graves y urgentes que plantean a la Iglesia tanto la aspiración contemporánea a la liberación como los movimientos de liberación que le hacen eco más o menos fielmente. No es posible olvidar nj un sólo instante las situaciones de miseria dramática de donde brota la interpelación así lanzada a los téblogos.

2. La experiencia radical de la libertad cristiana ${ }^{3}$ constituye aquí el primer punto de referencia. Cristo, nuestro Liberador, nos ha librado del pecado, y de la esclavitud de la ley y de la carne, que es la señal de la condición del hombre pecador. Es pues la vida nueva de gracia, fruto de la justificacion, la que nos hace libres. Esto significa que la esclavitud más radical es la esclavitud del pecado. Las otras formas de esclavitud encuentran pues en la esclavitud del pecado su última raíz. Por esto la libertad en pleno sentido cristiano, caracterizada por la vida en el Espíritu, no podrá ser confundida con la licencia de ceder a los deseos de la carne. Ella es vida nueva en la caridad.

3. Las "teologías de la liberación" tienen en cuenta ampliamente la narra- 
cion del Exodo. En efecto, éste constituye el acontecimiento fundamental en la formación del pueblo elegido. Es la liberación de la dominación extranjera y de la esclavitud. Se considera que la significación especlfica del acontecimiento le viene de su finalidad, pues esta liberación está ordenada a la fundación del pueblo de Dios y al culto de la Alianza celebrado en el Monte Sinaí. ${ }^{4}$ Por esto la liberación del Exodo no puede referirse a una liberación de naturaleza principal y exclusivamente politica. Por otra parte es significativo que el término $\mathrm{l}$ beración sea a veces reemplazado en la Escritura por el otro, muy cercano, de redención.

4. El episodio que originó el Exodo jamás se borrará de la memoria de Israel. A él se hace referencia cuando, después de la ruina de Jerusalén y el Exilio a Babilonia, se vive en la esperanza de una nueva liberación y, más allá, en la espera de una liberación definitiva. En esta experiencia, Dios es reconocido como el Liberador. El sellará con su pueblo una Nueva Alianza, marcada con el don de su Espíritu y la conversión de los corazones. ${ }^{5}$

5. Las múltiples angustias y miserias experimentadas por el hombre fiel al Dios de la Alianza proporcionan el tema a varios salmos: lamentos, llamadas de socorro, acciones de gracias hacen mención de la salvación religiosa y de la liberacion. En este contexto, la angustia no se identifica pura y simplemente con una condición social de miseria o con la de quien sufre la opresion política. Contiene además la hostilidad de los enemigos, la injusticia, la muerte, la falta. Los salmos nos remiten a una experiencia religiosa esencial: sólo de Dios se espera la salvación y el remedio. Dios, y no el hombre, tiene el poder de cambiar las situaciones de angustia. Así los "pobres del Señor" viven en una dependencia total y de confianza en la providencia amorosa de Dios. ${ }^{6}$ Y por otra parte, durante toda la travesia del desierto, el Seffor no ha dejado de proveer a la liberación y la purificación espiritual de su pueblo.

6. En el Antiguo Testamento los Profetas, después de Amós, no dejan de recordar, con particular vigor, las exigencias de la justicia y de la solidaridad, y de hacer un juicio extremamente severo sobre los ricos que oprimen al pobre. Toman la defensa de la viuda y del huérfano. Lanzan amenazas contra los poderosos: la acumulación de iniquidades no puede conducir más que a terribles castigos. Por esto la fidelidad a la Alianza no se concibe sin la práctica de la justicia. La justicia con respecto a Dios y la justicia con respecto a los hombres son inseparables. Dios es el defensor y el liberador del pobre.

7. Tales exigencias se encuentran en el Nuevo Testamento. Aún más, están radicalizadas, como lo muestra el discurso sobre las Bienaventuranzas. La conversión y la renovación se deben realizar en lo más hondo del corazón.

8. Ya anunciado en el Antiguo Testamento, el mandamiento del amor fraterno extendido a todos los hombres constituye la regla suprema de la vida social. ${ }^{7}$ No hay discriminaciones o limites que puedan oponerse al reconocimiento de todo hombre como el projiimo. ${ }^{8}$

9. La pobreza por el Reino es magnificada. Y en la figura del Pobre, somos llevados a reconocer la imagen y como la presencia misteriosa del Hijo de Dios que se ha hecho pobre por amor hacia nosotros. ${ }^{9}$ Tal es el fundamento de 
las palabras inagotables de Jesús sobre el Juicio en $M I 25,35-46$. Nuestro Senor es solidario con toda miseria: toda miseria está marcada por su presencia.

10. Al mismo tiempo, las exigencias de la justicia y de la misericordia, ya anunciadas en el Antiguo Testamento, se profundizan hasta el punto de revestir en el Nuevo Testamento una significación nueva. Los que sufren o están perseguidos son identificados con Cristo. ${ }^{10} \mathrm{La}$ perfección que Jesús pide a su discípulos $(M t 5,18)$ consiste en el deber de ser misericordioso "como vuestro Padre es misericordioso"' ( $L c 6,36)$.

11. A la luz de la vocación cristiana al amor fraterno y a la misericordia, los ricos son severamente llamados a su deber. ${ }^{11}$ San Pablo, ante los desórdenes de la Iglesia del Corinto, subraya con fuerza el vinculo que existe entre la participación en el sacramento del amor y el compartir con el hermano que está en la necesidad. ${ }^{12}$

12. La Revelación del Nuevo Testamento nos enseffa que el pecado es el más profundo, que alcanza al hombre en lo más íntimo de su personalidad. La primera liberación, a la que han de hacer referencia todas las otras, es la del pecado.

13. Sin duda, para sefialar el carácter radical de la liberación traída por Cristo, of recida a todos los hombres, ya sean políticamente libres o esclavos, el Nuevo Testamento no exige en primer lugar, como presupuesto para la entrada en esta libertad, un cambio de condición polltica y social. Sin embargo, la Carta a Filemón muestra que la nueva libertad, traída por la gracia de Cristo, debe tener necesariamente repercusiones en el plano social.

14. Consecuentemente no se puede restringir el campo del pecado, cuyo primer efecto es introducir el desorden en la relación entre el hombre y Dios, a lo que se denomina "pecado social." En realidad, sólo una justa doctrina del pecado permite insistir sobre la gravedad de sus efectos sociales.

15. No se puede tampoco localizar el mal principal y únicamente en las "estructuras" económicas, sociales o políticas malas, como si todos los otros males se derivasen, como de su causa, de estas estructuras, de suerte que la creación de un "hombre nuevo" dependiera de la inslauración de estructuras economicas y sociopoliticas diferentes. Ciertamente hay estructuras inicuas y generadoras de iniquidades, que es preciso tener la valentía de cambiar. Frutos de la acción del hombre, las estructuras, buenas o malas, son consecuencias antes de ser causas. La raiz del mal reside, pues, en las personas libres y responsables, que deben ser convertidas por la gracia de Jesucristo, para vivir y actuar como criaturas nuevas, en el amor al projimo, la búsqueda eficaz de la justicia, del dominio de si y del ejercicio de las virtudes. ${ }^{13}$

Cuando se pone como primer imperativo la revolución radical de las relaciones sociales y se cuestiona, a partir de aquí, la búsqueda de la perfección personal, se entra en el camino de la negación del sentido de la persona y de su trascendencia, y se arruina la ética y su fundamento que es el carácter absoluto de la distinción entre el bien y el mal. Por otra parte, siendo la caridad el principio de la auténtica perfección, esta última no puede concebirse sin apertura a los otros y sin espíritu de servicio. 


\section{La voz del magisterlo}

1. Para responder al desafio lanzado a nuestra época por la opresion y el hambre, el Magisterio de la lglesia, preocupado por despertar las conciencias cristianas en el sentido de la justicia, de la responsabilidad social y de la solidaridad con los pobres y oprimidos, ha recordado repetidas veces la actualidad y la urgencia de la doctrina y de los imperativos contenidos en la Revelación.

2. Contentémonos con mencionar aquí algunas de estas intervenciones: los documentos pontificios más recientes: Mater et Magistra y Pacem in terris, Populorum progressio, Evangelii nuntiandi. Mencionemos igualmente la Carta al Cardenal Roy, Octogesima adveniens.

3. El Concilio Vaticano II, a su vez, ha abordado las cuestiones de la justicia y de la libertad en la Constitucion pastoral Gaudium et spes.

4. El Santo Padre ha insistido en varias ocasiones sobre estos temas, especialmente en las Encíclicas Redemptor hominis, Dives in misericordia y Laborem exercens. Las numerosas intervenciones recordando la doctrina de los derechos del hombre tocan directamente los problemas de la liberación de la per. sona humana respecto a los diversos tipos de opresión de la que es victima. A este propósito es necesario mencionar especialmente el Discurso pronunciado ante la XXXVI Asamblea general de la O.N.U. en Nueva York, el 2 de octubre de $1979.1^{14}$ El 28 de enero del mismo año, Juan Pablo II, al inaugurar la III Conferencia del CELAM en Puebla, habia recordado que la verdad sobre el hombre es la base de la verdadera liberación. ${ }^{15}$ Este texto constituye un documento de referencia directa para la teologia de la liberación.

5. Por dos veces, en 1971 y 1974, el Sinodo de los Obispos ha abordado temas que se refieren directamente a una concepción cristiana de la liberación: el de la justicia en el mundo y el de la relación entre la liberación de las opresiones y la liberación integral o la salvación del hombre. Los trabajos de los Sinodos de 1971 y de 1974 llevaron a Pablo VI a precisar en la Exhortación Apostolica Evangelii nuntiandi los lazos entre evangelización y liberación o promoción humana. ${ }^{16}$

6. La preocupación de la Iglesia por la liberación y por la promoción humana se ha manifestado también mediante la constitución de la Comisión Pontificia Justicia y Paz. ${ }^{16}$

7. Numerosos son los Episcopados que, de acuerdo con la Santa Sede, han recordado también la urgencia y los caminos de una auténtica liberación cristiana. En este contexto, conviene hacer una mención especial de los documentos de las Conferencias Generales del Episcopado latinoamericano en Medellin en 1968 y en Puebla en 1979. Pablo VI estuvo presente en la apertura de Medellin, Juan Pablo II en la de Puebla. Uno y otro abordaron el tema de la conversión y de la liberación.

8. En la línea de Pablo VI, insistiendo sobre la especificidad del mensaje del Evangelio, ${ }^{17}$ especificidad que deriva de su origen divino, Juan Pablo II, en el discurso de Puebla, ha recordado cuáles son los tres pilares sobre los que debe apoyarse toda teologia de la liberación auténtica: la verdad sobre Jesucristo, la verdad sobre la Iglesia, la verdad sobre el hombre. ${ }^{18}$ 


\section{Una nueva interpretación del cristianismo}

1. No se puede olvidar el ingente trabajo desinteresado desarrollado por cristianos, pastores, sacerdotes, religiosos o laicos que, impulsados por el amor a sus hermanos que viven en condiciones inhumanas, se esfuerzan en llevar ayuda y alivio a las inumerables angustias que son fruto de la miseria. Entre ellos, algunos se preocupan de encontrar medios eficaces que permitan poner fin lo más rápidamente posible a una situación intolerable.

2. El celo y la compasion que deben estar presentes en el corazon de todos los pastores corren el riesgo de ser desviados y proyectados hacia empresas tan ruinosas para el hombre y su dignidad como la miseria que se combate, si no se presta suficiente atencion a ciertas tentaciones.

3. El angustioso sentimiento de la urgencia de los problemas no debe hacer perder de vista lo esencial, ni hacer olvidar la respuesta de Jesús al Tentador $(M i 4,4)$ : "No sólo de pan vive el hombre, sino de toda palabra que sale de la boca de Dios" (Dr 8, 3). Así, ante la urgencia de compartir el pan, algunos se ven tentados a poner entre paréntesis y a dejar para el mañana la evangelización: en primer lugar el pan, la Palabras para más tarde. Es un error mortal al separar ambas cosas hasta oponerlas entre si. Por otra parte, el sentido cristiano sugiere espontáneamente lo mucho que hay que hacer en uno y otro sentido. 19.

4. Para otros, parece que la lucha necesaria por la justicia y la libertad humanas, entendidas en su sentido económico y político, constituye lo esencial y el todo de la salvacion. Para éstos, el Evangelio se reduce a un evangelio puramente terrestre.

5. Las diversas teologlas de la liberación se sitúan, por una parte, en relacion con la opción preferencial por los pobres reafirmada con fuerza y sin ambiguedades, despues de Medellin, en la Conferencia de Puebla, ${ }^{20}$ y por otra, en la tentación de reducir el Evangelio de la salvación a un evangelio terrestre.

6. Recordemos que la opción preferencial definida en Puebla es doble: por los pobres y los jovenes. ${ }^{21}$ Es significativo que la opción por la juventud se haya mantenido totalmente en silencio.

7. Anteriormente hemos dicho (cf. IV, 3) que hay una auténtica "teologia de la liberación", la que está enraizada en la Palabra de Dios, debidamente interpretada.

8. Pero, desde un punto de vista descriptivo, conviene hablar de las teologias de la liberación, ya que la expresión encubre posiciones teológicas, o a veces también ideológicas, no solamente diferentes, sino también a menudo incompatibles entre si.

9. El presente documento sólo tratará de las producciones de la corriente del pensamiento que, bajo el nombre de "teologia de la liberacion" proponen una interpretación innovadora del contenido de la fe y de la existencia cristiana que se aparta gravemente de la fe de la Iglesia, aún más, que constituye la negociación práctica de la misma. 
10. Préstamos no criticados de la ideología marxista y el recurso a las tesis de una hermenéutica bíblica dominada por el racionalismo son la raiz de la nueva interpretación, que viene a corromper lo que tenía de auténtico el generoso compromiso inicial en favor de los pobres.

\section{El análisis marxista}

1. La impaciencia y una voluntad de eficacia han conducido a ciertos cristianos, desconfiando de todo otro método, a refugiarse en lo que ellos llaman "el análisis marxista."

2. Su razonamiento es el siguiente: una situación intolerable y explosiva exige una acción eficaz que no puede esperar más. Una acción eficaz supone un análisis cientifico de las causas estructurales de la miseria. Ahora bien, el marxismo ha puesto a punto los instrumentos de tal análisis. Basta pues aplicarlos a la situación del Tercer Mundo, y en especial a la de América Latina.

3. Es evidente que el conocimiento científico de la situación y de los posibles caminos de transformación social es el presupuesto para una acción capaz de conseguir los fines que se han fijado. En ello hay una señal de la seriedad del compromiso.

4. Pero el tèrmino "científico" ejerce una fascinación casi mítica, y todo lo que lleva la etiqueta de cientifico no es de por sí realmente científico. Por esto precisamente la utilización de un método de aproximación a la realidad debe estar precedido de un examen crítico de naturaleza epistemológica. Este previo examen crítico le falta a más de una "teologia de la liberación."

5. En las ciencias humanas y sociales, conviene ante todo estar atento a la pluralidad de los métodos y de los puntos de vista, de los que cada uno no pone en evidencia más que un aspecto de una realidad que, en virtud de su complejidad, escapa a la explicación unitaria y univoca.

6. En el caso del marxismo, tal como se intenta utilizar, la critica previa se impone tanto más cuanto que el pensamiento de Marx constituye una concepción totalizante del mundo en la cual numerosos datos de observación y de análisis descriptivo son integrados en una estructura filosofico-ideológica, que impone la significación y la importancia relativa que se les reconoce. Los a priori ideologicos son presupuestos para la lectura de la realidad social. Asl, la disociación de los elementos hererogéneos que componen esia amalgama epistemológicamente hibrida llega a ser imposible, de tal modo que creyendo aceptar solamente lo que se presenta como un análisis, resulta obligado aceptar al mismo tiempo la ideologia. Asi no es raro que sean los aspectos ideológicos los que predominan en los préstamos que muchos de los "teólogos de la liberacion" toman de los autores marxistas.

7. La llamada de atención de Pablo VI sigue siendo hoy plenamente actual: a través del marxismo, tal como es vivido concretamente, se pueden distinguir diversos aspectos y diversas cuestiones planteadas a los cristianos para la reflexión y la acción. Sin embargo, "seria ilusorio y peligroso llegar a olvidar el intimo vínculo que los une radicalmente, aceptar los elementos del análisis marxista sin reconocer sus relaciones con la ideologia, entrar en la práctica 
de la lucha de clases y de su interpretacion marxista dejando de percibir el tipo de sociedad totalitaria a la cual conduce este proceso.'22

8. Es verdad que desde los origenes, pero de manera más acentuada en los últimos afos, el pensamiento marxista se ha diversificado para dar nacimiento a varias corrientes que divergen notablemente una de otras. En la medida en que permanecen realmente manxistas, estas corrientes continúan sujetas a un cierto número de tesis fundamentales que no son compatibles con la concepción cristiana del hombre y de la sociedad. En este contexto, algunas formulas no son neutras, pues conservan la significación que han recibido en la doctrina marxista. "La lucha de clases" es un ejemplo. Esta expresión conserva la interpretación que Marx le dio, y no puede en consecuencia ser considerada como un equivalente, con alcance empirico, de la expresión "conflicto social agudo." Quienen utilizan semejantes fórmulas, pretendiendo sólo mantener algunos elementos del análisis maxista, por otra parte rechazado en su totalidad, suscitan por lo menos una grave ambigüedad en el espiritu de sus lectores.

9. Recordemos que el ateísmo y la negación de la persona humana, de su libertad y de sus derechos, están en el centro de la concepción marxista. Esta contiene pues errores que amenazan directamente las verdades de la fe sobre el destino eterno de las personas. Aún más, querer integrar en la teologia un "análisis" cuyos criterios de interpretación dependen de esta concepción atea, es encerrarse en ruinosas contradicciones. El desconocimiento de la naturaleza espiritual de la persona conduce a subordinarla totalmente a la colectividad y, por tanto, a negar los principios de una vida social y política conforme con la dignidad humana.

10. El examen critico de los métodos de análisis tomados de otras disciplinas se impone de modo especial al teblogo. La luz de la fe es la que provee a la teologia sus principios. Por esto la utilización por la teologia de aportes filosóficos o de las ciencias humanas tiene un valor "instrumental" $y$ debe ser objeto de un discernimiento crítico de naturaleza teológica. Con otras palabras, el criterio último y decisivo de verdad no puede ser otro, en última instancia, que un criterio teológico. La validez o grado de validez de todo lo que las otras disciplinas proponen, a menudo por otra parte de modo conjetural, como verdades sobre el hombre, su historia y su destino, hay que juzgarla a la luz de la fe y de lo que esta nos ensefla acerca de la verdad del hombre y del sentido último de su destino.

11. La aplicación a la realidad económica, social y politica de hoy de esquemas de interpretación tomados de la corriente del pensamiento marxista puede presentar a primera vista alguna verosimilitud, en la medida en que la situación de ciertos paises of rezca algunas analoglas con la que Marx describió e interpreto a mediados del siglo pasado. Sobre la base de estas analogias se hacen simplificaciones que, al hacer abstraccion de factores esenciales especificos, impiden de hecho un análisis verdaderamente riguroso de las causas de la miseria, y mantienen las confusiones.

12. En ciertas regiones de América Latina, el acaparamiento de la gran mayorla de las riquezas por una oligarquia de propietarios sin conciencia so- 
cial, la casi ausencia o las carencias del Estado de derecho, las dictaduras militares que ultrajan los derechos elementales del hombre, la corrupción de ciertos dirigentes en el poder, las prácticas salvajes de cierto capital extranjero, constituyen olros tantos factores que alimentan un violento sentimiento de revolución en quienes se consideran víctimas impotentes de un nuevo colonialismo de orden tecnológico, financiero, monetario o económico. La toma de conciencia de las injusticias está acompañada de un pathos que toma prestado a menudo su razonamiento del marxismo, presentado abusivamente como un razonamiento "científico."

13. La primera condición de un análisis es la total docilidad respecto a la realidad que se describe. Por esto una conciencia critica debe acompañar el uso de las hipótesis de trabajo que se adoptan. Es necesario saber que éstas corresponden a un punto de vista particular, lo cual tiene como consecuencia inevitable subrayar unilateralmente algunos aspectos de la realidad, dejando los otros en la sombra. Esta limitación, que fluye de la naturaleza de las ciencias sociales, es ignorada por quienes, a manera de hipótesis reconocidas como tales, recurren a una concepción tolalizante como es el pensamiento de Marx.

\section{Subversión del sentido de la verdad y violencia}

1. Esta concepción totalizante impone su lógica y arrastra las "teologias de la liberación" a aceptar un conjunto de posiciones incompatibles con la visión cristiana del hombre. En efecto, el núcleo ideológico, tomado del marxismo, al cual hace referencia, ejerce la función de un principio determinante. Esta función se le ha dado en virtud de la calificación de científico, es decir, de necesariamente verdadero, que se le ha atribuido. En este núcleo se pueden distinguir varios componentes.

2. En la lógica del pensamiento marxista. "el análisis" no es separable de la praxis y de la concepción de la historia a la cual está unida esta praxis. El análisis es así un instrumento de crítica, y la crítica no es más que un momento de combate revolucionario. Este combate es el de la clase del Proletariado investido de su misión histórica.

3. En consecuencia sólo quien participa en este combate puede hacer un análisis correcto.

4. La conciencia verdadera es asi una conciencia partidaria. Se ve que la concepción misma de la verdad en cuestión es la que se encuentra totalmente subvertida: se pretende que sólo hay verdad en y por la praxis partidaria.

5. La praxis, y la verdad que de ella deriva, son praxis y verdad partidarias, ya que la estructura fundamental de la historia está marcada por la lucha de clases. Hay pues una necesidad objetiva de entrar en la lucha de clases (la cual es el reverso dialéctico de la relación de explotación que se denuncia). La verdad es verdad de clase, no hay verdad sino en el combate de la clase revolucionaria.

6. La ley fundamental de la historia que es la ley de la lucha de clases implica que la sociedad está fundada sobre la violencia. A la violencia que constituye la relación de dominación de los ricos sobre los pobres deberá res- 
ponder la contra-violencia revolucionaria mediante la cual se invertirá esta relación.

7. La lucha de clases es pues presentada como una ley objetiva, necesaria. Entrando en su proceso, al lado de los oprimidos, se "hace" la verdad, se actúa "científicamente." En consecuencia, la concepción de la verdad va a la par con la afirmación de la violencia necesaria, y por ello con la del amoralismo politico. En estas perspectivas, pierde todo sentido la referencia a las exigencias éticas que ordenan reformas estructurales $\mathrm{e}$ institucionales radicales y valerosas.

8. La ley fundamental de la lucha de clases tiene un carácter de globalidad y de universalidad. Se refleja en todos los campos de la existencia, religiosos, éticos, culturales e institucionales. Con relación a esta ley, ninguno de estos campos es autónomo. Esta ley constituye el elemento determinante en cada uno.

9. Por concesion hecha a las tesis de origen marxista, se pone radicalmente en duda la naturaleza misma de la ética. De hecho, el carácter trascendente de la distinción entre el bien y el mal, principio de la moralidad, se encuentra implícitamente negado en la óptica de la lucha de clases.

\section{Traducción "leológíca" de r jle núcleo}

1. Las posiciones presentadas aquí se encuentran a veces tal cual en algunos escritos de los "teólogos de I ، liberación." En otros, proceden lógicamente de sus premisas. Por otra parte, en ellas se basan algunas practicas litúrgicas, como por ejemplo "la Eucaristía" transformada en celebración del pueblo en lucha, aunque quienes participan en estas prácticas no sean plenamente conscientes de ello. Uno se encuentra pues delante de un verdadero sistema, aun cuando algunos duden ile seguir la logica hasta el final. Este sistema como tal es una perversion del me nsaje cristiano tal como Dios lo ha confiado a su Iglesia. Asi, pues, este mensilje se encuentra cuestionado en su globalidad por las "teologías de la liberacion."

2. Lo que estas "teologías de la liberación" han acogido como un principio, no es el hecho de las estratificaciones sociales con las desigualdades $e$ injusticias que se les agregan, sino la teorla de la lucha de clases como ley estructural fundamental de la historia. Se saca la conclusión de que la lucha de clases entendida así divide a la Iglesia y que en función de ella hay que juzgar las realidades eclesiales. También se pretende que es mantener, con mala fe, una ilusion enganfosa el afirmar que el amor, en su universalidad, puede vencer lo que constituye la ley estructural primera de la sociedad capitalista.

3. En esta concepción, la lucha de clases es el motor de la historia. La historia llega a ser asi una noción central. Se afirmará que Dios se hace historia. Se afladirá que no hay más que una sola historia, en la cual no hay que distinguir ya entre historia de la salvación e historia profana. Mantener la distinción sería caer en el "dualismo." Semejantes afirmaciones reflejan un inmanentismo historicista. Por esto se tiende a identificar el Reino de Dios y su devenir con el movimiento de la liberacion humana, y a hacer de la historia misma el 
sujeto de su propio desarrollo como proceso de la autorredención del hombre a través de la lucha de clases. Esta identificación está en oposición con la fe de Ia Iglesia, tal como la ha recordado el Concilio Vaticano II. ${ }^{23}$

4. En esta linea, algunos llegan hasta el limite de identificar a Dios y la historia, y a definir la fe como "fidelidad a la historia," lo cual significa fidelidad comprometida en una práctica política conforme a la concepción del devenir de la humanidad concebido como un mesianismo puramente temporal.

5. En consecuencia, la fe, la esperanza y la caridad reciben un nuevo contenido: ellas son "ficlelidad a la historia," "confianza en el futuro," "opción por los pobres:" que es como negarlas en su realidad teologal.

6. De esta nueva concepción se sigue inevitablemente una politización radical de las afirmaciones de la fe y de los juicios teológicos. Ya no se trata solamente de atraer la atención sobre las consecuencias e incidencias políticas de las verdades de fe, las que serian respetadas ante todo por su valor trascendente. Se trata más bien de la subordinación de toda afirmación de la fe o de la teología a un criterio político dependiente de la teoria de la lucha de clases, motor de la historia.

7. En consecuencia, se presenta la entrada en la lucha de clases como una exigencia de la caridad como tal; se denuncia como una actitud estática y contraria al amor a los pobres la voluntad de amar desde ahora a todo hombre, cualquiera que sea su pertenencia de clase, $y$ de ir a su encuentro por los caminos no violentos del diálogo y de la persuasión. Si se afirma que el hombre no debe ser objeto de odio, se afirma igualmente que en virtud de su pertenencia objetiva al mundo de los ricos, él es ante todo un enemigo de clase que hay que combatir. Consecuentemente la universalidad del amor al prójimo y la fraternidad llegan a ser un principio escatológico, válido sólo para el "hombre nuevo" que surgirá de la revolución victoriosa.

8. En cuanto a la Iglesia, se tiende a ver en ella sólo una realidad interior de la historia, que obedece también a las leyes que se suponen dirigen el devenir histórico en su inmanencia. Esta reducción vacia la realidad específica de la Iglesia, don de la gracia de Dios y misterio de fe. Igualmente, se niega que tenga todavía sentido la participación en la misma Mesa eucarística de cristianos que por otra parte pertenecen a clases opuestas.

9. En su significacion positiva, la Iglesia de los pobres significa la preferencia, no exclusiva, dada a los pobres, según todas las formas de miseria humana, ya que ellos son los preferidos de Dios. La expresion significa también la toma de conciencia de las exigencias de la pobreza evangélica en nuestro tiempo, por parte de la Iglesia, - como comunión y como institución- así como por parte de sus miembros.

10. Pero las "leologías de la liberación," que tienen el mérito de haber valorado los grandes textos de los Profetas y del Evangelio sobre la defensa de los pobres, conducen a un amalgama ruinosa entre el pobre de la Escritura y el proletariado de Marx. Por ello el sentido cristiano del pobre se pervierte y el combate por los derechos de los pobres se transforma en combate de clase en la 
perspectiva ideológica de la lucha de clases. La Iglesia de los pobres significa así una lglesia de clase, que ha tomado conciencia de las necesidades de la lucha revolucionaria como etapa hacia la liberacion y que celebra esta liberación en su liturgia.

11. Es necesario hacer una observación análoga respecto a la expresión Iglesia del pueblo. Desde el punto de vista pastoral, se puede entender por ésta los destinatarios prioritarios de la evangelización, aquellos hacia los cuales, en virtud de su condición, se dirige ante todo el amor pastoral de la Iglesia. Se puede también referir a la lglesia como "pueblo de Dios," es decir, como el pueblo de la Nueva Alianza sellada en Cristo. ${ }^{24}$

12. Pero las "teologías de la liberación," de las que hablamos, entienden por Iglesia del pueblo una Iglesia de clase, la Iglesia del pueblo oprimido que hay que "concientizar" en vista de la lucha liberadora organizada. El pueblo así entendido llega a ser también para algunos, objeto de la fe.

13. A partir de tal concepción de la Iglesia del pueblo, se desarrolla una critica de las estructuras mismas de la lglesia. No se trata solamente de una corrección fraternal respecto a los pastores de la Iglesia cuyo comportamiento no refleja el espiritu evangélico de servicio y se une a signos anacrónicos de autoridad que escandalizan a los pobres. Se trata de poner en duda la estructura sacramental y jerárquica de la Iglesia, tal como la ha querido el Señor. Se denuncia la jerarquia y el Magisterio como representantes objetivos de la clase dominante que es necesario combatir. Teológicamente, esta posición vuelve a decir que el pueblo es la fuente de los ministerios y que se puede dotar de ministros a elección propia, según las necesidades de su misión revolucionaria histórica.

\section{Una nueva hermenéutica}

1. La concepción partidaria de la verdad que se manifiesta en la praxis revolucionaria de clase corrobora esta posición. Los teblogos que no comparten las tesis de la "teología de la liberación," la jerarquia, y sobre todo el Magisterio romano son asi desacreditados a priori, como pertenecientes a la clase de los opresores. Su teología es una teología de clase. Argumentos y enseñanzas no son examinados en si mismos, pues sólo reflejan los intereses de clase. Por ello, su contenido es decretado, en principio, falso.

2. Aquí aparece el carácter global y totalizante de la "teologia de la liberación." Esta, en consecuencia, debe ser criticada, no en tal o cual de sus afirmaciones, sino a nivel del punto de vista de clase que adopta a priori y que funciona en ella como un principio hermenéutico determinante.

3. A causa de este presupuesto clasista, se hace extremamente dificil, por no decir imposible, obtener de algunos "teólogos de la liberación" un verdadero diálogo en el cual el interlocutor sea escuchado y sus argumentos sean discutidos objetivamente y con atención. Porque estos teólogos parten, más o menos conscientemente, del presupuesto de que el punto de vista de la clase oprimida y revolucionaria, que sería la suya, constituye el único punto de vista de la verdad. Los criterios teológicos de verdad se encuentran asi relativizados 
y subordinados a los imperativos de la lucha de clases. En esta perspectiva, se substituye la ortodoxia como recta regla de la fe, por la idea de ortopraxis como criterio de verdad. A este respecto, no hay que confundir la orientacion práctica, propia de la teología tradicional al igual y con el mismo titulo que la orientación especulativa, con un primado privilegiado reconocido a un cierto tipo de praxis. De hecho, esta última es la praxis revolucionaria que llegaría a ser el supremo criterio de la verdad teológica. Una sana metodología teologica tiene en cuenta sin duda la praxis de la Iglesia en donde encuentra uno de sus fundamentos, en cuanto que deriva de la fe y es su expresion vivida.

4. La doctrina social de la Iglesia es rechazada con desdén. Se dice que procede de la ilusion de un posible compromiso, propio de las clases medias que no tienen destino historico.

5. La nueva hermenéurica inscrita en las "teologías de la liberación" conduce a una relectura esencialmente política de la Escritura. Por tanto se da mayor importancia al acontecimiento del Exodo en cuanto que es liberación de la esclavitud politica. Se propone igualmente una lectura politica del Magnificat. El error no está aquí es prestarle atención a una dimensión política de los relatos biblicos. Está en hacer de esta dimensión la dimensión principal y exclusiva, que conduce a una lectura reductora de la Escritura.

6. Igualmente, se sitúa en la perspectiva de un mesianismo temporal, el cual es una de las expresiones más radicales de la secularización del Reino de Dios y de su absorción en la inmanencia de la historia humana.

7. Privilegiando de esta manera la dimensión política, se ha llegado a negar la radical novedad del Nuevo Testamento $y$, ante todo, a desconocer la persona de Nuestro Señor Jesucristo, verdadero Dios y verdadero hombre, al igual que el carácter específico de la liberación que nos aporta, y que es ante todo liberación del pecado, el cual es la fuente de todo los males.

8. Por otra parte, al dejar a un lado la interpretación autorizada del Magisterio, denunciada como interpretación de clase, se descarta al mismo tiempo la Tradición. Por esto, se priva de un criterio teológico esencial de interpretación y, en el vacio así creado, se acogen las tesis más radicales de la exégesis racionalista. Sin espíritu crítico se vuelve a la oposición entre el "Jesús de la historia" y el "Jesús de la fe."

9. Es cierto que se conservan literalmente las formulas de la fe, en particular la de Calcedonia, pero se le atribuye una nueva significación, lo cual es una negación de la fe de la Iglesia. Por un lado se rechaza la doctrina cristológica ofrecida por lo Tradicion, en nombre del criterio de clase; por otro, se pretende alcanzar el "Jesús de la historia" a partir de la experiencia revolucionaria de la lucha de los pobres por su liberación.

10. Se pretende revivir una experiencia análoga a la que habria sido la de Jesús. La experiencia de los pobres que lucha por su liberación - la cual habria sido la de Jesús-, revelaría ella sola el conocimiento del verdadero Dios y del Reino.

11. Está claro que se niega la fe en el Verbo encarnado, muerto y resucita- 
do por todos los hombres, y que "Dios ha hecho Señor y Cristo."25 Se le substituye por una "figura" de Jesús que es una especie de símbolo que recapitula en si las exigencias de la lucha de los oprimidos.

12. Así se da una interpretacion exclusivamente politica de la muerte de Cristo. Por ello se niega su valor salvífico y toda la economia de la redención.

13. La nueva interpretación abarca asi el conjunto del misterio cristiano.

14. De manera general, opera lo que se puede llamar una inversion de los simbolos. En lugar de ver con S. Pablo, en el Exodo, una figura del bautismo, ${ }^{26}$ se llega al límite de hacer de él un símbolo de la liberación política del pueblo.

15. Al aplicar el mismo criterio hermeneutico a la vida eclesial y a la constitución jerárquica de la lglesia, las relaciones entre la jerarquía y la "base" llegan a ser relaciones de dominacion que obedecen a la ley de la lucha de clases. Se ignora simplemente la sacramentalidad que está en la raiz de los ministerios eclesiales y que hace de la Iglesia una realidad espiritual irreductible a un análisis puramente sociológico.

16. La inversión de los símbolos se constata también en el campo de los sacramentos. La Eucaristía ya no es comprendida en su verdad de presencia sacramental del sacrificio reconciliador, y como el don del Cuerpo y de la Sangre de Cristo. Se convierte en celebración del pueblo que lucha. En consecuencia, se niega radicalmente la unidad de la Iglesia. La unidad, la reconciliación, la comunión en el amor ya no se conciben como don que recibimos de Cristo. ${ }^{27}$ La clase historica de los pobres es la que construye la unidad, a través de su lucha. La lucha de clases es el camino para esta unidad. La Eucaristla llega a ser asi Eucaristia de clase. Al mismo tiempo se niega la fuerza triunfante del amor de Dios que se nos ha dado.

\section{Orientaciones}

1. La llamada de atención contra las graves desviaciones de ciertas "teologías de la liberación" de ninguna manera debe ser intrepretada como una aprobación, aun indirecta, dada a quienes contribuyen al mantenimiento de la miseria de los pueblos, a quienes se aprovechan de ella, a quienes se resignan o a quienes deja indiferentes esta miseria. La Iglesia, guiada por el Evangelio de la Misericordia y por el amor al hombre, escucha el clamor por la justicia ${ }^{28}$ y quiere responder a él con todas sus fuerzas.

2. Por tanto, se hace a la Iglesia un profundo llamamiento. Con audacia y valentia, con clarividencia y prudencia, con celo y fuerza de ánimo, con amor a los pobres hasta el sacrificio, los pastores - como muchos ya lo hacen-, considerarán tarea prioritaria el responder a esta llamada.

3. Todos los sacerdotes, religiosos y laicos que, escuchando el clamor por la justicia, quieran trabajar en la evangelización y en la promoción humana, lo harán en comunion con sus obispos y con la Iglesia, cada uno en la linea de su especifica vocación eclesial.

4. Conscientes del carácter eclesial de su vocación, los teólogos colabora- 
rán lealmente y en espiritu de diálogo con el Magisterio de la Iglesia. Sabrán reconocer en el Magisterio un don de Cristo a su Iglesia ${ }^{29}$ y acogerán su palabra y sus instrucciones con respeto filial.

5. Las exigencias de la promoción humana y de una liberación auténtica, solamente se comprenden a partir de la tarea evangelizadora tomada en su inlegridad. Esta liber ación tiene como pilares indispensables la verdad sobre Jesucristo el Salvador, la verdad sobre la Iglesia, la verdad sobre el hombre y sobre su dignidad..$^{30}$ La Iglesia, que quiere ser en el mundo entero la Iglesia de los pobres, intenta servir a la noble lucha por la verdad y por la justicia, a la luz de las Bienaventuranzas, y ante todo de la bienaventuranza de los pobres de corazón. La Iglesia habla a cada hombre y, por lo tanto, a todos los hombres. Es "la Iglesia universal. La Iglesia del misterio de la encarnación. No es la Iglesia de una clase o de una sola casta. Ella habla en nombre de la verdad misma. Esta verdad es realista." Ella conduce a tener en cuenta "toda realidad humana, toda injusticia, toda tensión, toda lucha." 31

6. Una defensa eficaz de la justicia se debe apoyar sobre la verdad del hombre, creado a imagen de Dios y llamado a la gracia de la filiación divina. El reconocimiento de la verdadera relación del hombre con Dios constituye el fundamento de la justicia que regula las relaciones entre los hombres. Por esta razón la lucha por los derechos del hombre, que la Iglesia no cesa de recordar, constituye el auténtico combate por la justicia.

7. La verdad del hombre exige que este combate se lleve a cabo por medios conformes a la dignidad humana. Por esta razón el recurso sistemático y deliberado a la violencia ciega, venga de donde venga, debe ser condenado. ${ }^{32} \mathrm{El}$ tener confianza en los medios violentos con la esperanza de instaurar más justicia es ser víctima de una ilusión mortal. La violencia engendra violencia y degrada al hombre. Ultraja la dignidad del hombre en la persona de las víctimas y envilece esta misma dignidad en quienes la practican.

8. La urgencia de reformas radicales de las estructuras que producen la miseria y constituyen ellas mismas formas de violencia no puede hacer perder de vista que la fuente de las injusticias está en el corazón de los hombres. Solamente recurriendo a las capacidades éticas de la persona y a la perpetua necesidad de conversión interior se obtendrán los cambios sociales que estarán verdaderamente al servicio del hombre. ${ }^{33}$ Pues a medida que los hombres, conscientes del sentido de su responsabilidad, colaboran libremente, con su iniciativa y solidaridad, en los cambios necesarios, crecerán en humanidad. La inversión entre moralidad y estructuras conlleva una antropologia materialista incompatible con la verdad del hombre.

9. lgualmente es una ilusion mortal creer que las nuevas estructuras por si mismas darán origen a un "hombre nuevo," en el sentido de la verdad del hombre. El cristiano no puede desconocer que el Espíritu Santo, que nos ha sido dado, es la fuente de toda verdadera novedad y que Dios es el señor de la historia.

10. Igualmente, la inversión por la violencia revolucionaria de las estructuras generadoras de injusticia no es ipso facto el comienzo de la instauración 
de un régimen justo. Un hecho notable de nuestra época debe ser objeto de la reflexión de todos aquellos que quieren sinceramente la verdadera liberación de sus hermanos. Millones de nuestros contemporáneos aspiran legítimamente a recuperar las libertades fundamentales de las que han sido privados por regimenes totalitarios y ateos que se han apoderado del poder por caminos revolucionarios y violentos, precisamente en nombre de la liberación del pueblo. No se puede ignorar esta vergüenza de nuestro tiempo: pretendiendo aportar la libertad se mantiene a naciones enteras en condiciones de esclavitud indignas del hombre. Quienes se vuelven cómplices de semejantes esclavitudes, tal vez inconscientemente, traicionan a los pobres que intentan servir.

11. La lucha de clases como camino hacia la sociedad sin clases es un mito que impide las reformas y agrava la miseria y las injusticias. Quienes se dejan fascinar por este mito deberían reflexionar sobre las amargas experiencias históricas a las cuales han conducido. Comprenderán entonces que no se trata de ninguna manera de abandonar un camino eficaz de lucha en favor de los pobres en beneficio de un ideal sin efectos. Se trata, al contrario, de liberarse de un espejismo para apoyarse sobre el Evangelio y su fuerza de realización.

12. Una de las condiciones para el necesario enderezamiento teológico es la recuperación del valor de la enseñanza social de la Iglesia. Esta enseñanza de ningún modo es cerrada. Al contrario está abierta a todas las cuestiones nuevas que no dejan de surgir en el curso de los tiempos. En esta perspectiva, la contribución de los teólogos y pensadores de todas las regiones del mundo a la reflexión de la Iglesia es hoy indispensable.

13. Igualmente, la experiencia de quienes trabajan directamente en la evangelización y promocion de los pobres y oprimidos es necesaria para la reflexion doctrinal y pastoral de la Iglesia. En este sentido, hay que decir que se tome conciencia de ciertos aspectos de la verdad a partir de la praxis, si por ésta se entiende la práctica pastoral y una práctica social de inspiración evangélica.

14. La enseñanza de la Iglesia en materia social aporta las grandes orientaciones éticas. Pero, para que ella pueda guiar directamente la acción, exige personalidades competentes, tanto desde el punto de vista cientílico y técnico como en el campo de las ciencias humanas o de la política. Los pastores estarán atentos a la formación de tales personalidades competentes, viviendo profundamente del Evangelio. A los laicos, cuya misión propia es construir la sociedad, corresponde aquí el primer puesto.

15. Las tesis de las "teologias de la liberacion" son ampliamente difundidas, bajo una forma todavia simplificada, en sesiones de formación o en grupos de base que carecen de preparación catequética y teológica. Son asi aceptadas, sin que resulte posible un juicio crítico, por hombres y mujeres generosos.

16. Por esto los pastores deben vigilar la calidad y el contenido de la catequesis y de la formacion que siempre debe presentar la integridad del mensaje de la salvación y los imperativos de la verdadera liberación humana en el marco de este mensaje integral. 
17. En esta presentación integral del misterio cristiano, será oportuno acentuar los aspectos esenciales que las "teologias de la liberación" tienden especialmente a desconocer o eliminar: trascendencia y gratuidad de la liberación en Jesucristo, verdadero Dios y verdadero hombre, soberanía de su gracia, verdadera naturaleza de los medios de salvación, y en particular de la Iglesia y de los sacramentos. Se recordará la verdadera significación de la ética para la cual la distinción entre el bien y el mal no podrá ser relativizada, el sentido auténtico del pecado, la necesidad de la conversión y la universalidad de la ley del amor fraterno. Se pondrá en guardia contra una politización de la existencia que, desconociendo a un tiempo la especificidad del Reino de Dios y la trascendencia de la persona, conduce a sacralizar la política y a captar la religiosidad del pueblo en beneficio de empresas revolucionarias.

18. A los defensores de "la ortodoxia", se dirige a veces el reproche de pasividad, de indulgencia o de complicidad culpables respecto a situaciones de injusticia intolerables y de los regímenes políticos que las mantienen. La conversion espiritual, la intensidad del amor a Dios y al prójimo, el celo por la justicia y la paz, el sentido evangelico de los pobres y de la pobreza, son requeridos a todos, y especialmente a los pastores y a los responsables. La preocupación por la pureza de la fe ha de ir unida a la preocupación por aportar, con una vida teologal integral, la respuesta de un testimonio eficaz de servicio al prójimo, y particularmente al pobre y al oprimido. Con el testimonio de su fuerza de amar, dinámica y constructiva, los cristianos pondrán asi las bases de aquella "civilización del amor" de la cual ha hablado despues de Pablo VI, la Conferencia de Puebla. ${ }^{34}$ Por otra parte, son muchos, sacerdotes, religiosos y laicos, los que se consagran de manera verdaderamente evangélica a la creación de una sociedad justa.

\section{Conclusion}

Las palabras de Pablo VI, en el Credo del pueblo de Dios, expresan con plena claridad la fe de la Iglesia, de la cual no se puede apartar sin provocar, con la ruina espiritual, nuevas miserias y nuevas esclavitudes.

"Confesamos que el Reino de Dios iniciado aquí abajo en la Iglesia de Cristo no es de este mundo, cuya figura pasa, y que su crecimiento propio no puede confundirse con el progreso de la civilización, de la ciencia o de la técnica humanas, sino que consiste en conocer cada vez más profundamente las riquezas insondables de Cristo, en esperar cada vez con más fuerza los bienes eternos, en corresponder cada vez más ardientemente al Amor de Dios, en dispensar cada vez más abundantemente la gracia y la santidad entre los hombres. Es este mismo amor el que impulsa a la Iglesia a preocuparse constantemente del verdadero bien temporal de los hombres. Sin cesar de recordar a sus hijos que ellos no tienen una morada permanente en este mundo, los alienta también, en conformidad con la vocación y los medios de cada uno, a contribuir al bien de su ciudad terrenal, a promover la justicia, la paz y la fraternidad entre los hombres, a prodigar ayuda a sus hermanos, en particular a los más pobres y desgraciados. La intensa solicitud de la Iglesia, Esposa de Cristo, por las necesidades de los hombres, por sus alegrías y esperanzas, por sus penas y esfuer- 
zos, nace del gran deseo que tiene de estar presente entre ellos para iluminarlos con la luz de Cristo y juntar a todos en El, su único Salvador. Pero esta actitud nunca podrá comportar que la Iglesia se conforme con las cosas de este mundo ni que disminuya el ardor de la espera de su Seflor y del Reino eterno." 35

El Santo Padre Juan Pablo II, en el Iranscurso de una Audiencia concedida al infrascrito Prefecto, ha aprobado esta Instrucción, cuya preparación fue decidida en una reunión ordinaria de la Congregación para la Doctrina de la $F e, y$ ha ordenado su publicación.

Dado en Roma, en la Sede de la Congregación para la Doctrina de la Fe, el dia 6 de agosto de 1984, fiesta de la Transfiguración del Señor.

\section{JOSEPH Card. RATZINGER Prefecto}

\section{ALBERTO BOVONE \\ Arzobispo tit. de Cesarea di Numidia \\ Secretario}

NOTAS

1. Cr. Gaudium et spes, n. 4.

2. Cf. Dei Verbum, n. 10.

3. Cf. Gál S, 1 ss.

4. Cf. Ex 24.

5. Cf. Jer $31-34 ; E_{z} 36,26$ ss.

6. Cf. Sof 3, 12 ss.

7. Cf. Di 10, 18-19.

B. Cf. Le 10, 25-37.

9. Cr. $2 \operatorname{Cor} 8,9$.

10. Cf. MI 25, 31-46; Act 9, 4-5: Col 1, 24.

11. Cf. Sant S, 1 ss.

12. Cf. 1 Cor 11, 17-34.

13. Cf. Sant 2, 14-26.

14. Cf. AAS 71, 1979, pp. 1144-1160.

15. Cf. $A A S 71,1979$, p. 196.

16. Cf. Evangelii nuntiandi n. 25-33, AAS 68, 1976, pp. 23-28.

17. Cf. Evangelii nuntiandi n. 32, AAS 68, 1976, p. 27.

18. Cf. $A A S 71,1979$, pp. 188-196.

19. Cf. Gaudium el spes, n. 39; Pio XI, Quadragessimo anno: AAS 23, 1931, P. 207.

20. Cf. n. 1134-1165 y n. 1166-1205.

21. Cr. Doc. de Puebla, IV, 2.

22. PABLO VI, Ocrogesima adveniens, n. 34, AAS 63, 1971, pp. 424-425.

23. Cr. Lumen gentium, n. 9-17.

24. Cr. Gaudium et spes, n. 39.

25. Cr. Act 2, 36.

26. Cr. 1 Cor 10, 1-2.

27. Cf. Ef 2, 11-22.

28. Cf. Doc. de Puebla, 1, 2, n. 3.3.

29. Cr. LC 10,16.

30. Cf. JUAN PABLO II, Discurso para la apertura de la Conferencia de Puebla: AAS 71, 1979, p. 188-196; Doc. de Puebla, II, I. 
31. Cf. JUAN PABlo II, Discurso en la Favela "Vidigal" en Rio de Joneiro, 2 de julio de 1980. AAS 72, 1980, pp. 852-858.

32. CI. Doc. de Puebla, II, 2, n. 5. 4.

33. Cf. Doc, de Puebla, IV, 3, N. 3. 3.

34. Cf. Doc. de Puebla, IV, 2, n. 2. 4.

35. PABLO VI, Credo del pueblo de Dios, 30 de junio de 1968, AAS 60, 1968, pp. 443-44. 